\title{
A INCONSISTÊNCIA TEÓRICA E EMPÍRICA DA HIPÓTESE CENTRAL DO RENT SEEKING
}

\author{
Vinícius Eduardo Ferrari ${ }^{1}$
}

\begin{abstract}
Resumo
0 termo rent seeking diz respeito ao processo competitivo de apropriação das rendas artificiais criadas a partir da intervenção estatal na economia. Subjacente a esta teoria reside o pressuposto da total dissipação das rendas, ou seja, a visão de que a intervenção estatal na economia geraria rendas artificiais e que a perseguição destas transferências econômicas, pelos agentes privados, promoveria o desperdício de recursos produtivos num montante semelhante ao valor original das rendas engendradas a partir da ação pública. 0 presente artigo procura demonstrar que este cenário de dissipação total das rendas representa um caso particular e não uma propriedade geral imanente à ação estatal. Conclui-se que a teoria de rent seeking é incapaz de produzir resultados analíticos gerais e bem demonstrados. Assim, constata-se a fragilidade das prescrições políticas embasadas nesta construção teórica.
\end{abstract}

Palavras-chave: Rent-seeking. Transferências. Desperdício. Liberalismo econômico.

${ }^{1}$ Mestrando do Programa de Pós-Graduação em Ciência Política (IFCH/ UNICAMP).
vinicius_e_ferrari@yahoo.com.br 


\title{
THE CORE HYPOTHESIS OF RENT SEEKING: THEORETICAL AND EMPIRICAL INCONSISTENCIE
}

\begin{abstract}
The expression rent seeking refers to the competitive appropriation of rents originated from the state intervention in the economy. Underlying this idea, is the assumption of full rent dissipation or, in other words, the presumption that state intervention could generate artificial rents and that the pursuit of these economic transfers by private agents could promote waste of productive resources similar to the original value of the rents created by the state action. Through this present article, the author intends to demonstrate that this scenario of total dissipation is an isolated occurrence, and not a general property inherent to state action. It is possible to conclude that the theory of rent seeking is incapable of producing general analytical results. Hence, there is clear fragility of political decisions when based in this theory.
\end{abstract}

Keywords: Rent-seeking. Transfers. Waste. Economic liberalism.

\section{INTRODUÇÃO}

0 s teóricos da public choice definem renda como a parcela do pagamento para um detentor de recursos acima do valor que seria pago aos mesmos recursos num uso alternativo. Para esta vertente teórica, as rendas emanam de duas fontes. Elas surgem naturalmente no sistema de preços devido, por exemplo, a alterações nas curvas de oferta e demanda. As rendas também podem ser criadas artificialmente através da ação do governo. Neste caso, a intervenção governamental nos mecanismos concorrenciais próprios do mercado promoveria transferências de renda entre os distintos grupos sociais, por exemplo, entre produtores e consumidores. Ainda, de acordo com a public choice, os agentes privados gastarão recursos na captura e/ou na resistência de tais transferências. Estes gastos não ampliam o produto social e a perda de produção, resultante desta aplicação de recursos em atividades estéreis, representa um custo social para a sociedade. 0 montante total dos gastos alocados na perseguição destas transferências de renda tende a apresentar, no limite, a mesma magnitude do valor original da transferência. Este processo competitivo de apropriação das rendas 
artificiais, criadas a partir da intervenção estatal na economia, é denominado de rent seeking.

Este artigo procurará contestar a hipótese central subjacente à teoria do rent seeking, Isto é, o pressuposto da total dissipação das rendas/transferências, ou seja, a visão de que a intervenção estatal na economia geraria rendas, e que a perseguição destas rendas, pelos agentes privados, promoveria o desperdício de recursos produtivos em um montante semelhante ao valor original das transferências. Desta forma, pretende-se argumentar que este cenário de dissipação total dos recursos econômicos representa um caso particular e não uma propriedade geral imanente à ação estatal. Para tanto, resgataremos as obras dos principais estudiosos do rent seeking, em especial Gordon Tullock, Robert Tollinson e Willian Corocoran. Procuraremos evidenciar que nem mesmo os defensores/formuladores desta teoria conseguiram comprovar teoricamente 0 total desaparecimento das rendas oriundas da intervenção estatal na economia. Na seqüência, empreenderemos uma revisão da literatura sobre os testes empíricos da tese central do rent seeking. Estes testes foram incapazes de comprovar a dissipação dos recursos econômicos.

Optou-se pela divisão do artigo em quatro partes sobre os seguintes temas: o desenvolvimento da teoria de rent seeking; as prescrições de políticas públicas baseadas na teoria de rent seeking; a análise da consistência teórica e empírica do pressuposto da total dissipação das rendas oriundas da intervenção estatal. Finalmente, na conclusão, além de uma síntese das principais conclusões deste artigo, tecem-se alguns comentários a respeito da fragilidade das prescrições políticas embasadas na teoria do rent seeking.

\section{O DESENVOLVIMENTO DA TEORIA DE RENT SEEKING}

A teoria de rent seeking surge em um artigo publicado por Gordon Tullock em 1967. Nesta obra, o autor demonstra sua insatisfação em relação às análises econômicas a respeito das tarifas e monopólios prevalecentes no início da década de 1960. Segundo Tullock (1967, p. 224) as "ferramentas nas quais estes estudos estão fundamentados produzem uma subestimação dos custos em termos de bem estar das tarifas e monopólios". 
Gráfico 1 - Análises tradicionais sobre o monopólio

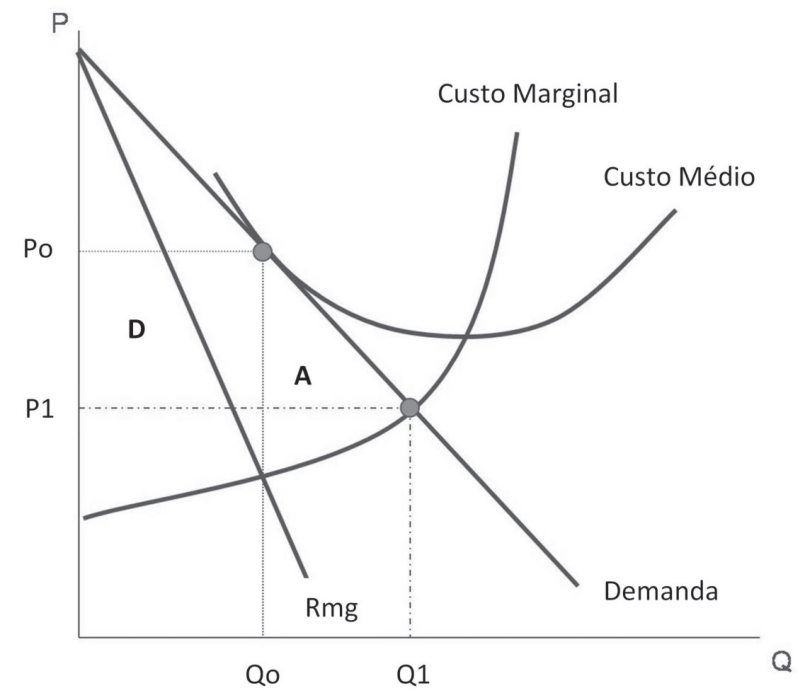

Fonte: Pindyck e Rubinfeld (1994, p. 451)

0 Gráfico 1 elucida as análises tradicionais a respeito dos custos sociais ocasionados pelo monopólio. Num mercado que opera sob concorrência perfeita, 0 preço cobrado por uma mercadoria iguala o custo marginal incorrido na produção do bem. Neste caso, os compradores consumiriam a quantidade eficiente. Quando um produtor se torna monopolista e eleva o preço (Po) acima do nível competitivo, ocorre uma redução da quantidade consumida. Os compradores, que continuam comprando a mercadoria ao novo preço Po, sofrem uma perda (retângulo D) exatamente compensada pela receita adicional obtida pelos vendedores mediante 0 preço mais alto. Os consumidores que deixam de adquirir o produto sofrem uma perda (triângulo A) não compensada por nenhum ganho dos vendedores. Nestas análises, o triângulo A representa o único custo social provocado pelo monopólio. 0 retângulo D é considerado meramente uma transferência dos consumidores para os produtores, fato que não proporcionaria a redução do produto da nacional.

Segundo Tullock (1967), a análise apresentada acima subestima os custos sociais do monopólio. A razão desta subestimação residiria na interpretação equivocada a respeito do impacto nulo das transferências de renda sobre 0 produto nacional: 0 "problema com as transferências de renda não é que elas diretamente infringem perdas de bem estar/riqueza, mas que elas levam as pessoas a empregar recursos na tentativa de obter ou prevenir tais transferências" 
(TULLOCK, 1967, p. 231). Os empresários interessados em obter o retângulo D dos consumidores investirão recursos nas tentativas de se tornarem monopolistas. Por sua vez, os consumidores provavelmente demonstrarão interesse em prevenir esta transferência e procurarão realizar investimentos para concretizar este fim:

Estas despesas, que em certa medida anulam uma à outra, são puro desperdício do ponto de vista da sociedade como um todo; elas não são gastas para aumentar a riqueza da sociedade, mas em tentativas de transferência ou resistência da renda existente (TULLOCK, 1967, p. 228, tradução nossa).

Desta forma, observa-se um custo social relacionado ao "produto perdido" dos recursos empregados nestas atividades improdutivas. Neste sentido, os custos de oportunidade dos recursos empregados na tentativa/resistência de transferências também devem ser incorporados ao custo social do monopólio 2 . Como vimos na introdução, estes gastos alocados na perseguição de transferências são denominados de rent seeking.

Qual o montante de recursos que os agentes gastarão em rent seeking? Segundo Tullock (1967, p. 231), empresários racionais destinariam recursos à tentativa de se formar um monopólio até o momento em que o custo marginal destes recursos igualasse o retorno descontado do direito de monopólio. Caso os lucros esperados pelo monopólio excedessem os custos marginais, "a competição na atividade de se obter um monopólio induzirá as firmas competidoras a contratar inputs adicionais no intuito de encampar uma parcela adicional dos lucros do monopólio" (POSNER, 1975, p. 809). A aquisição de novos imputs, conseqüentemente, elevaria os custos marginais das atividades de rent seeking. As novas aquisições prosseguiriam até o momento em que os custos marginais igualassem o retorno marginal esperado do monopólio. Neste ponto, toda a renda gerada pelo monopólio seria dissipada. Neste sentido, "a riqueza dos consumidores não é transferida para os detentores de firmas monopolistas; ela é (toda) dissipada na compra dos inputs relacionados a atividade de se tornar monopolista" (POSNER, 1975, p. 821).

Em síntese, tanto para Tullock (1967) quanto para Posner (1975), os recursos gastos pelos empresários para capturar o retângulo D, do Gráfico 1,

\footnotetext{
2 Tullock (1967) considera esta situação análoga à questão do roubo na sociedade. A transferência de riqueza da vítima para o ladrão não envolve uma redução do conjunto de bens da sociedade. No entanto, não se pode derivar a partir deste fato que o custo social do roubo seja zero. A oportunidade para tais transferências atrairá recursos para as atividades ladinas e também para a proteção contra o roubo. Os custos de oportunidade dos recursos consumidos nestas duas atividades representarão os custos sociais do roubo na sociedade.
} 
também devem ser incluídos no custo social do monopólio³. Uma vez que no limite estes gastos serão semelhantes ao valor do retângulo D, ou seja, o valor total da transferência, o custo social do monopólio equivalerá ao trapézio formado pela soma do triângulo A com o retângulo D no Gráfico 1.

Gráfico 2 - Análise tradicional sobre proteção tarifária no Comércio Internacional

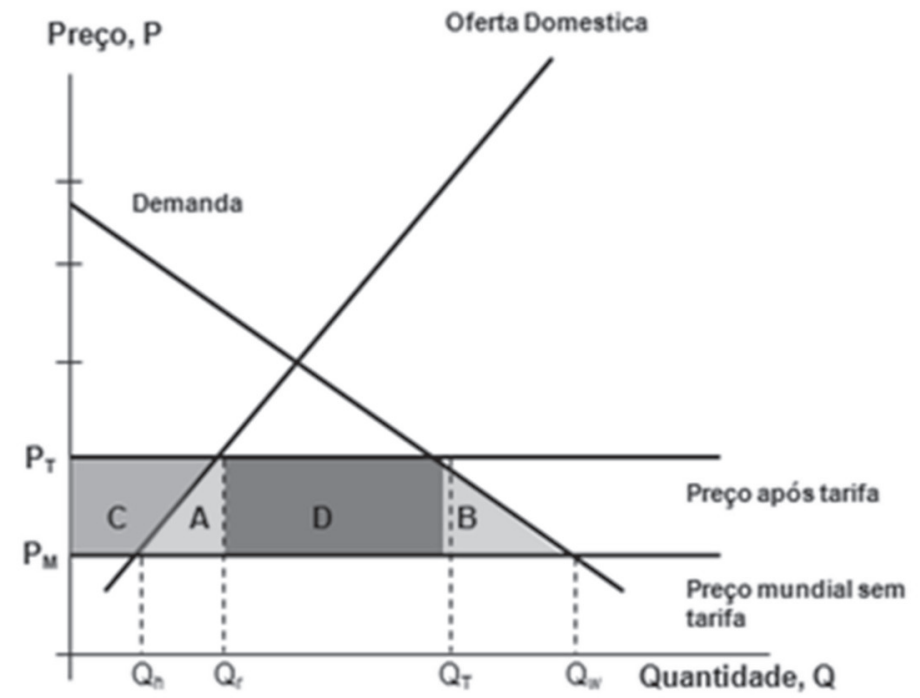

Fonte: Adaptado de Tullock (2003, p. 2).

Tullock (1967) também estende suas críticas ao tratamento da literatura econômica tradicional a respeito dos efeitos do protecionismo tarifário sobre 0 comércio internacional. De acordo com estas análises, no período anterior à tarifa,

\footnotetext{
${ }^{3}$ Posner (1975, p. 812) apresenta um interessante exemplo a respeito do processo de dissipação das rendas do monopólio. 10 competidores disputam uma transferência no valor de $\$ 100.000$. Se as propostas não são reembolsáveis e todos os candidatos são neutros a riscos, cada um deles oferecerá \$ 10.000 pelo direito de se tornar um monopolista. No âmbito social, a renda do monopólio é completamente dissipada. $\$ 100.000$ foi gasto para capturar $\$ 100.000$. Este exemplo também ressalta um aspecto importante, também reconhecido por Tullock (1967). Existem empresas que não possuem um monopólio, mas que "apostaram" recursos na esperança de obter uma transferência. Os custos totais do monopólio devem ser mensurados em termos dos esforços para se obter um monopólio, o que inclui tanto as tentativas sem sucesso quanto as tentativas exitosas.
} 
Qw mercadorias eram consumidas ao preço mundial. A produção nacional era Qh e 0 total de importações Qw-Qh. Após a implementação da tarifa, o consumo total cairá para Qt, e a produção nacional crescerá até Qr. De acordo com esta visão, os triângulos A e B representam o custo social associado à tarifa. B consiste na perda social resultante da queda do consumo. Por sua vez, A representa o desperdício líquido dos recursos empregados em uma estrutura produtiva ineficiente. D (transferência dos produtores internacionais para o governo) e C (transferência dos consumidores para os produtores nacionais) não são considerados custos sociais. Tullock (1967) considera que esta análise subestima o custo social total associado à tarifa:

[nas análises tradicionais, o trapézio C] parece ser considerado meramente uma transferência e comumente não é incluso no custo social da tarifa... Olhando para este assunto de forma dinâmica, existe outro custo social envolvido e sua magnitude é função do tamanho do trapézio de transferência (C). Geralmente, governos não impõem tarifa por vontade própria. Eles necessitam receber lobbies ou serem pressionados através do gasto de recursos [por parte dos agentes que desejam ser beneficiados] em atividades políticas. É possível estimar que os produtores domésticos invistam recursos no lobby pela tarifa até que o retorno marginal do último dólar gasto desta forma iguale 0 retorno produzido pela transferência. Também podem existir outros interesses que buscam prevenir a transferência e investem recursos para influenciar 0 governo nesse outro sentido. Estes gastos [...] são puro desperdício do ponto de vista da sociedade como um todo (TULLOCK, 1967, p. 228).

Em 1974, Anne Krueger publicou um artigo a respeito das restrições quantitativas de importações presentes na Índia e na Turquia. De acordo com 0 raciocínio presente nesta obra, as quotas de importações proporcionam lucros para as empresas situadas nestes países. Elas possibilitam que as firmas importem mercadorias ao preço mundial (inferior ao preço doméstico) e, posteriormente, revendam estas mercadorias ao preço doméstico no mercado interno. Desta forma, as empresas competirão pelos lucros mediante a competição pelos direitos de importação racionados pelo governo. Por conseqüência, segundo Krueger (1974), os empresários racionais/maximizadores destinarão recursos para influenciar os administradores públicos que concedem as licenças de importação. Em uma situação de competição, ou seja, de busca de lucros adicionais propiciados por novas licenças, os gastos alocados em atividades de rent seeking (por exemplo, o suborno dos funcionários) se elevarão; no limite estes gastos tendem a igualar a renda esperada das quotas. Neste sentido, as rendas geradas a partir das restrições 
ao comércio internacional serão completamente dissipadas devido à concorrência pelas licenças de importação. Cabe ainda ressaltar que o estudo conduzido por Krueger (1974) empreendeu a primeira estimativa empírica dos custos sociais de rent seeking. A autora sugere que 7\% do PIB da Índia era desperdiçado e 15\% do PIB da Turquia era perdido devido ao rent seeking por licenças de importação $0^{4}$.

Buchanan (1980) e Tollison (1982) identificam três níveis nos quais o rent seeking pode ocorrer, uma vez que uma escassez artificial é criada pelo governo. No exemplo escolhido por Buchanan (1980), o governo decide limitar o número de táxis; desta forma os detentores das licenças para o exercício desta profissão obterão lucros. 0 primeiro nível, no qual ocorre o rent seeking, diz respeito à tentativa de persuadir as autoridades governamentais, no sentido de obter um tratamento favorável na distribuição das licenças. 0 segundo nível contempla os gastos dos indivíduos empreendidos na tentativa de ingresso no funcionalismo público, em um cenário no qual o rendimento dos cargos públicos é muito superior aos salários da iniciativa privada, em parte, em razão dos subornos pagos pelos taxistas na tentativa de influenciar a distribuição das licenças. Buchanan (1980) supõe uma terceira situação na que as licenças de táxi serão leiloadas e o valor obtido será disperso, através do orçamento do Estado, mediante aumento das despesas públicas e/ou redução de impostos. Também neste caso os "[...] custos de rent seeking ocorrerão uma vez que os indivíduos procurarão se tornar membros dos grupos favorecidos pelo programa de gastos públicos/ renúncias fiscais" (TOLLINSON, 1982, p. 579). Em síntese, os indivíduos poderão: (1) gastar recursos com lobby político, (2) procurar entrar na política para garantir acesso ao processo de tomada de decisões, (3) omitir potenciais rendimentos para obter tratamento fiscal privilegiado. A conclusão de Buchanan (1980, p. 14) é clara: "[...] recursos podem ser desperdiçados através dos três níveis simultaneamente".

\section{VISÕES DOS TEÓRICOS DO RENT SEEKING SOBRE A AÇÃO DO ESTADO: OS EFEITOS PREJUDICIAIS DA INTERVENÇÃO ESTATAL SOBRE AS ATIVIDADES ECONÔMICAS}

Buchanan (1980, p. 3) define renda como "a parte do pagamento para um detentor de recursos acima do valor que seria pago aos mesmos recursos num uso alternativo. Renda é uma receita que excede o custo de oportunidade". Conforme ressalta Tollison (1982), as rendas emanam de duas fontes. Elas surgem

\footnotetext{
${ }^{4}$ Já Posner (1975) estimou que cerca de 3\% do PIB americano era perdido devido aos custos sociais do monopólio.
} 
naturalmente no sistema de preços devido, por exemplo, a alterações nas curvas de oferta e demanda. Por sua vez, "estes retornos excedentes são tipicamente considerados de vida curta (quasi-rents) porque a competição irá conduzi-los aos níveis normais" (TOLLISON, 1982, p. 575). 0 pagamento de rendas para alguns detentores de recursos atrairá novos empresários para o respectivo setor econômico. À medida que essa nova entrada ocorre, as rendas recebidas inicialmente tendem a cair e, no limite, todas as rendas desaparecerão. A perseguição das rendas criadas sob estas condições é denominada de profit seeking. As rendas também podem ser criadas artificialmente através da intervenção governamental na economia. A competição pelas rendas artificiais é denominada de rent seeking. 0 primeiro caso gerará resultados positivos e potencializará a eficiência econômica5. Por sua vez, quando as rendas são criadas pelo governo, os custos sociais emergem:

[...] se o processo pelo qual as rendas são criadas é sujeito a competição [...] os recursos gastos na busca por transferências gerarão desperdícios do ponto de vista da sociedade. Estes gastos não ampliam o produto social e 0 seu custo de oportunidade constitui uma perda de produção para a sociedade (TOLLISON, 1982, p. 576).

Buchanan (1980) ressalta que o comportamento individual racional é semelhante nas duas situações (profit seeking e rent seeking). As conseqüências não intencionais de ações individuais maximizadoras mudam daquelas classificadas como "boas para aquelas que parecem ser ruins, não porque os indivíduos se tornaram seres diferentes e alteraram suas ações, mas devido às alterações na estrutura institucional" (BUCHANAN, 1980, p. 4, grifo nosso). Neste sentido, a presença de mercados auto-regulados geraria sinergias positivas para a sociedade, enquanto a configuração institucional resultante da intervenção estatal na economia promoveria o desperdício. As citações abaixo evidenciam este último ponto:

[as rendas serão criadas] se a ação governamental se move muito além dos limites definidos pelo Estado mínimo ou de proteção, se o governo decide a interferir nos processos de ajustamento do mercado [...]. A atividade de rent seeking está diretamente relacionada ao escopo e ao alcance da atividade governamental na economia, ao tamanho do setor público. [...] Licenças governamentais, quotas, autorizações, aprovações, permissões - cada um

\footnotetext{
${ }^{5}$ No profit seeking "[...] a procura de novas oportunidades para obter rendas econômicas gera um processo contínuo de realocação de recursos que assegura 0 crescimento e 0 desenvolvimento econômico" (BUCHANAN, 1980, p. 5).
} 
destes termos próximos implica numa escassez arbitrária e/ou artificial criada pelo governo. Esta escassez implica na emergência de rendas, o que por sua vez implica o surgimento de atividades de rent seeking. As pessoas investirão recursos escassos tanto na tentativa de assegurar as atribuições de direitos iniciais sobre as rendas criadas artificialmente quanto na tentativa de reverter estas atribuições iniciais. Em cada caso, e a despeito da racionalidade individual dos investimentos, recursos valiosos serão desperdiçados no processo (BUCHANAN, 1980, p. 9).

Em síntese, Buchanan (1980) parece sugerir que qualquer intervenção estatal na economia conduzirá ao desperdício de recursos escassos. Neste sentido, a autoridade governamental deveria se concentrar apenas nas atividades relacionadas à segurança e evitar a adoção de políticas públicas que interferissem nos processos alocativos conduzidos pelo mercado.

A análise empreendida por Krueger (1974), a respeito do impacto da atuação do Estado na economia, apresenta alguns pontos de contato com as proposições de Buchanan (1980). Segundo a autora, nas economias de mercado as restrições governamentais à atividade econômica são fatos perniciosos. Estas restrições dariam origem a rendas e à conseqüente competição pelas rendas acarretaria em custos econômicos para a sociedade. Para Krueger (1974), as quotas de importação representam o caso mais amplo e visível de rent seeking. No entanto, este fenômeno social seria muito mais abrangente:

A legislação de salário mínimo suscita níveis de equilíbrio onde desemprego se encontra acima do valor ótimo. Desta forma, ocorrem pesos mortos [deadweight losses]. 0 tabelamento [pelo governo] das taxas de juros e 0 conseqüente racionamento de crédito conduz à competição por empréstimos e depósitos e encare as operações bancárias [...] 0 tratamento fiscal aos ganhos de capital resulta num excesso de construção de apartamentos [...] E assim por diante. Cada uma dessas e das demais intervenções públicas levará as pessoas a competir por rendas embora os competidores não percebam que eles estão agindo desta forma. Em cada caso existe uma perda econômica superior ao triângulo tradicional (KRUEGER, 1974, p. 301-302).

Krueger (1974, p. 302) visualiza a possibilidade de a regulação estatal desencadear um ciclo vicioso: os indivíduos percebem que os mecanismos de mercado não funcionam de acordo com as metas sociais devido ao rent seeking. "Um consenso político, portanto, emerge para o governo intervir novamente no mercado, o que conseqüentemente ampliará o rent seeking e disso resultarão 
novas intervenções". Posner (1975) parece compartilhar com Krueger (1974) os temores sobre o crescimento da regulação estatal. 0 primeiro autor considera que a "regulação pública é provavelmente uma fonte de custo social superior ao monopólio privado" (POSNER, 1975, p. 821).

Dessas abordagens parece resultar a conclusão geral de que os mecanismos de mercado promovem a alocação ótima de recursos. Diante deste fato, toda intervenção estatal nas atividades econômicas gerará rent seeking e o conseqüente desperdício de recursos econômicos daí proveniente.

\section{O RENT SEEKING PROMOVERÁ O TOTAL DESPERDÍCIO DAS RENDAS E TRANSFERÊNCIAS?}

Alguns estudos posteriores dentro da própria public choice passaram a questionar as conclusões resumidas na seção anterior. Tullock (1980) elabora um modelo de rent seeking, no qual a dissipação total das rendas pode ocorrer ou não. De acordo com este modelo, o total dos gastos em rent seeking pode ser maior, igual ou inferior ao valor do prêmio criado artificialmente pelo Estado; o resultado dependeria do número de competidores e do custo marginal de se influenciar a probabilidade de vitória na competição. A partir deste artigo pioneiro de Gordon Tullock, iniciou-se um debate no âmbito do mainstream a respeito deste tema. Estes pontos são importantes e merecem ser detalhados.

\section{O MODElo ElabORADO POR GORDON TullOCK EM 1980}

Tullock (1980) propõe um jogo no qual os competidores participariam de uma espécie de loteria. 0 jogo apresentaria as seguintes regras: "cada competidor pode comprar quantos tickets ele desejar a um dólar cada, os tickets da loteria são colocados numa urna, um deles é retirado e o detentor do ticket sorteado ganha o prêmio" (TULLOCK, 1980, p. 99). Ademais o prêmio da loteria assume o valor de US\$100. 0 valor gasto nos tickets da loteria será retido pela loteria, ou seja, não será adicionado ao prêmio. "Isso faz com que o jogo seja semelhante ao rent seeking, onde os recursos também são desperdiçados" (idem). Os competidores, por sua vez, tentarão maximizar o retorno esperado de seus investimentos (V). 0 retorno esperado pelo jogador A (Va) é dado pela equação abaixo:

$$
V a=\left[a^{r} /\left(a^{r}+b^{r}\right)\right] P-a \quad \text { Equação (1) }
$$


Neste caso, a e b são os gastos dos jogadores A e B; P o valor do prêmio/ payoff; $(\mathrm{a} / \mathrm{a}+\mathrm{b})$ representa a função de probabilidade de vitória e $\mathrm{r}$ reflete $\mathrm{a}$ facilidade de se afetar probabilidade de vitória. Por sua vez, r apresentará um comportamento inverso em relação aos custos marginais das atividades destinadas a afetar a probabilidade de vitória. Retomando a analogia apresentada no parágrafo anterior, quando $\mathrm{r}$ cresce o custo marginal dos investimentos em rent seeking decresce e vice-versa. Desta forma, $r$ indiretamente determinará "a forma da curva de custo de marginal" (TULLOCK, 1980, p. 101) das atividades de rent seeking.

À luz da equação (1) qual seria o gasto ótimo individual, ou seja, quanto cada competidor investiria? Inicialmente devemos avaliar o caso mais simples, ou seja, um jogo de dois jogadores $(n=2)$ onde $r=1$. Neste exemplo, "a probabilidade de vitória do jogador A é igual à razão entre o número de tickets que ele comprou e o número total de tickets comprados" (CORCORAN, 1984, p. 89). A primeira vista, a maioria das pessoas acharia que "a aposta apropriada é \$50, mas essa aposta promove a equiparação do retorno total com o custo total ao invés de igualar as margens" (TULLOCK, 1980, p. 100-101). Conforme demonstra Tullock (1980), caso o jogo permitir ajustes marginais, a solução para o exemplo acima ( $n=2$ jogadores e $r=1$ ) será um gasto individual de $\$ 25$. Se o jogador A gastar $\$ 26$ e o jogador B gastar a quantia ótima de $\$ 25$, o valor esperado do investimento do jogador A será de $\$ 50,98$ (basta o leitor substituir os valores no primeiro termo da equação 1). Se o jogador A reduzir seu investimento de $\$ 26$ para $\$ 25$, o valor do prêmio esperado será de $\$ 50$. 0 jogador A economizou $\$ 1$ e o valor esperado do prêmio se reduziu em apenas 0,98 . Neste caso, o jogador A teve um ganho marginal de $\$ 0,02$. Por sua vez, se o jogador A investir $\$ 24$ e o jogador B manter a aposta em $\$ 25$, o jogador A reduzirá o valor esperado do seu investimento em $\$ 1,02$ e apenas economizará \$1.Quando ambos os jogadores gastarem \$25, desaparecem os incentivos para a realização de ajustes marginais e o jogo tem o seu equilíbrio.

Em outros termos, se o jogo permitir ajustes marginais nas apostas, os jogadores procurarão igualar o custo de um ticket adicional ao incremento propiciado por este ticket adicional no valor esperado do investimento. Desta forma, ocorre a equiparação do custo marginal com o retorno marginal (equiparação das margens), condição considerada necessária para a maximização dos retornos individuais. A tradução desta condição para a linguagem matemática e a determinação do gasto ótimo de cada jogador se processa da seguinte forma: "um processo de reação de Cournot é empregado, onde a equação (1) é diferenciada 
e a derivada é igualada a zero. Isso resulta numa solução de equilíbrio CounortNash" (CORCORAN, 1984, p. 90), que associa o investimento individual (a) ao número de jogadores (n) e também a r .Cada um dos n competidores gastará6:

$$
a=\frac{(n-1) r}{n^{2}} P \quad \text { Equação (2) }
$$

Uma vez que cada jogador individual gastará uma quantia semelhante, quando se multiplica a equação (2) por n, obtém- se o gasto total em rent seeking empreendido por todos os jogadores (T):

$$
\mathrm{T}=\frac{(\mathrm{n}-1) \mathrm{r}}{\mathrm{n}} \mathrm{P}^{\text {Equação (3) }}
$$

Com base nas equações (2) e (3), Tullock (1980) procurou calcular o valor dos investimentos individuais e o investimento total em rent seeking para as diferentes combinações de $\mathrm{n}$ e $\mathrm{r}$, num cenário que se estabelece um prêmio de $\$ 100$. Os resultados podem ser observados nas tabelas abaixo.

\begin{tabular}{|c|c|c|c|c|c|}
\hline Exponent & 2 & 4 & 10 & & 15 \\
\hline $1 / 3$ & 8.33 & 6.25 & 3.00 & & 2.07 \\
\hline $1 / 2$ & 12.50 & 9.37 & 4.50 & I & 3.11 \\
\hline 1 & 25.00 & 18.75 & 9.00 & & 6.22 \\
\hline 2 & 50.00 & 37.50 & 18.00 & & $\overline{12.44}$ \\
\hline 3 & 75.00 & 56.25 & 27.00 & & 18.67 \\
\hline 5 & 125.00 & 93.75 & 45.00 & II & 31.11 \\
\hline 8 & 200.00 & 150.00 & 72.00 & & 49.78 \\
\hline \multirow[t]{2}{*}{12} & 300.00 & 225.00 & 108.00 & & 74.67 \\
\hline & & & & & \\
\hline
\end{tabular}

Tabela 1 - Investimentos Individuais em Rent SeekingNúmero de Jogadores

Fonte: Tullock (1980, p. 102)

\footnotetext{
${ }^{6}$ Convém apresentarmos a resolução do exemplo citado no parágrafo anterior, ou seja, a solução para um jogo onde $n=2, r=1$ e $P=100$. Com base na equação (2), obtemos a seguinte operação matemática: $\frac{(2-1) * 1}{2 * 2} * 100=25$.

Desta forma obtemos a solução ótima \$25, ressaltada por Tullock (1980).
} 
Tabela 2 - Investimentos Totais em Rent Seeking Número de Jogadores

\begin{tabular}{|c|c|c|c|c|c|c|}
\hline Exponent & 2 & 4 & 10 & 15 & & Limit \\
\hline $1 / 3$ & 16.66 & 25.00 & 30.00 & 31.05 & & 33.30 \\
\hline $1 / 2$ & 25.00 & 37.40 & 45.00 & 46.65 & I & 50.00 \\
\hline 1 & 50.00 & 75.00 & 90.00 & 93.30 & & 100.00 \\
\hline 2 & 100.00 & 150.00 & 80.00 & 186.60 & & 200.00 \\
\hline 3 & 150.00 & 225.00 & 270.00 & 280.05 & & 300.00 \\
\hline 5 & 250.00 & 375.00 & 450.00 & 465.65 & II & 500.00 \\
\hline 8 & 400.00 & 600.00 & 720.00 & 746.70 & & 800.00 \\
\hline 12 & 600.00 & 900.00 & $1,080.00$ & 1.120 .05 & & $1,200.00$ \\
\hline
\end{tabular}

Fonte: Tullock (1980, p. 102)

Tullock (1980) divide as duas tabelas em três áreas. Na área I o somatório dos investimentos individuais de equilíbrio registra um valor igual ou inferior ao valor do prêmio. Neste caso nem todas as rendas são dissipadas. Por exemplo, quando o "[...] expoente (r) é um terço ou um meio, mesmo no limite existe um lucro de $\$ 66,66$ ou $\$ 50,00$ para os jogadores como um todo. Assim, alguns lucros permanecem" (TULLOCK, 1980, p. 103). Na área II, os gastos individuais são inferiores a \$100, no entanto, o somatório destes gastos superará o valor do prêmio estabelecido (situação denominada de overbidding). Para um jogo com 2 jogadores e expoente 3, "cada jogador pagará \$75 por uma chance cinqüenta-cinquenta sobre (um prêmio esperado) de \$50, o que pode parecer ser estúpido 7" (TULLOCK, 1980, p. 106). Esta constatação poderia levar os competidores a desistir de participar do jogo. No entanto, conforme assinala Tullock (1980), a regra geral de não jogar poder ser viciada pelo fato que se todos os jogadores seguirem esta regra menos um, ele poderá obter elevados lucros jogando. Na área III, os jogadores individuais realizam pagamentos superiores ao valor do prêmio. Tullock (1980) direciona pouca atenção para esta área. Uma vez que os jogadores ampliariam sua riqueza não jogando, seria improvável que as pessoas participassem de jogos dessa natureza.

As tabelas 3.1; 3.2 e também a equação (3) fornecem as bases para as recomendações de políticas públicas de Tullock (1980), destinadas a minimizar 0 total de recursos desperdiçados em rent seeking. Primeiramente, o autor assinala a necessidade de minimizar o número de competidores envolvidos na atividade de rent seeking. Isso resultaria numa diminuição do valor do termo (n-1)/n da equação (3). Por exemplo, se $\mathrm{n}=1$, os gastos totais em rent seeking seriam zero. Em segundo lugar, a função de custo marginal, que afeta a probabilidade de

\footnotetext{
${ }^{7}$ Basta o leitor substituir os valores na equação (1). Neste caso, se obterá um (Va) negativo igual a - \$25.
} 
vitória, deveria apresentar a máxima inclinação positiva possível (isso equivaleria a minimizar 0 valor do expoente ${ }^{8}$ ). Desta forma, seria desejável para o governo "estabelecer instituições... [que garantissem] custos marginais elevados" (TULLOCK, 1980, p. 104) para as atividades de rent seeking.

Ao apresentar seu modelo, Tullock (1980) efetua uma crítica ao tratamento até então direcionado ao fenômeno de rent seeking: "A maioria dos estudos assume implicitamente ou explicitamente que a atividade de rent seeking desconta toda a renda que foi gerada. Infelizmente, isso não é necessariamente verdade; a realidade é muito mais complicada (TULLOCK, 1980, p. 97).

Fiani (2003) destaca o impacto contestador das idéias presentes em Tullock (1980) sobre os demais estudos sobre o rent seeking. Segundo o economista brasileiro, na região II, os argumentos tradicionais são fortalecidos, de uma forma até mesmo inesperada, para seus primeiros analistas: a renda dissipada pode ser maior do que o valor do prêmio. "0 problema para a análise de rent seeking é, contudo, a região I, uma vez que ela não permite afirmar que a busca de direitos concedidos pelo Estado" (FIANI, 2003, p. 7) necessariamente conduzirá à "dissipação total da renda e ao conseqüente desperdício de recursos daí proveniente" (FIANI, 2003, p. 5), já que a dissipação total não ocorre com qualquer comportamento dos custos marginais.

\section{O DEBATE EM TORNO DA DISSIPAÇÃO DAS RENDAS NO LONGO PRAZO}

Corcoran (1984) considera que modelo de Tullock (1980) apresenta um escopo limitado. Este modelo se restringiria ao curto prazo, uma vez que cada solução deste modelo é dada para um número fixo de jogadores. Desta forma, os resultados obtidos seriam análogos à solução de equilíbrio de curto prazo obtida para os setores econômicos que operam sob a estrutura de concorrência perfeita (por sua vez, no modelo de concorrência perfeita, o curto prazo é caracterizado pela existência de um número fixo de firmas ${ }^{9}$ ). A constatação de que as rendas

\footnotetext{
${ }^{8}$ As despesas totais em rent seeking variam diretamente com o valor de $\mathrm{r}$, isto é, inversamente com o custo marginal. Por exemplo, num jogo com dois jogadores, a alteração "de um expoente $r=1 / 3$, que representa uma curva de custo bastante inclinada positivamente, para um expoente $r=2$, que representa uma (curva de custo) muito mais horizontal, propiciará um aumento de seis vezes nos pagamentos individuais e totais (TULLOCK, 1980, p. 104). Vide tabelas 3.1 e 3.2

${ }^{9}$ A diferenciação entre curto e longo prazo para os mercados que operam sob concorrência
} 
não seriam completamente dissipadas no curto prazo pelas atividades de rent seeking agregaria poucas informaç̧ões úteis às discussões teóricas uma vez que, nos mercados que operam sob concorrência perfeita, alguns setores também apresentam no curto prazo rendas econômicas acima dos custos de oportunidade:

Presumivelmente o pressuposto que o total das despesas [em rent seeking] iguala o payoff deve ser feito com uma perspectiva de longo prazo em mente, uma vez que é no longo prazo que o modelo de concorrência perfeita possui esta propriedade (CORCORAN, 1984, p. 90).

Desta forma, Corcoran (1984) considera crucial incorporar considerações de longo prazo ao modelo de Tullock (1980) para (re)estimar a despesa total atraída por um dado jogo/prêmio. "A consideração crucial para a determinação da solução de longo prazo é a possibilidade de entrada e saída no processo de rent seeking" (CORCORAN, 1984, p. 91). Se a taxa de retorno oferecida pela opção de rent seeking for positiva os competidores entrarão; caso contrário os competidores sairão. Em outros termos, “[...] a decisão de entrar no jogo levará em consideração a existência de lucros positivos o que é dado por" (CORCORAN, 1984, p. 91).

$$
\begin{aligned}
& \mathrm{P} / \mathrm{n}-\mathrm{a}>0 \\
& \frac{\mathrm{P}}{\mathrm{n}}-\frac{(\mathrm{n}-1) \mathrm{r}}{\mathrm{n}^{2}} \mathrm{P}>0 \\
& \mathrm{P} \frac{\mathrm{n}+\mathrm{r}-\mathrm{nr}}{\mathrm{n}^{2}}>0 \quad \text { Equação (4) }
\end{aligned}
$$

"O equilíbrio de longo prazo ocorre quando o incentivo para a entrada é dissipado, isto é, quando os lucros esperados forem iguais a 0" (CORCORAN, 1984, p. 93). Desta forma, o incentivo para a entrada será dissipado no momento que a equação (4) cair para zero, o que ocorre quando:

$$
\mathrm{n}=\frac{\mathrm{r}}{\mathrm{r}-1} \quad \text { Equação }(5)
$$

perfeita obedece à seguinte lógica: No curto prazo, o montante de capital investido num setor e o número de firmas serão considerados fixos. Somente ocorrerão variações do fator de produção trabalho. No longo prazo, os investimentos em capital variarão e desta forma também poderá ocorrerá a entrada de novas firmas no setor. Desta forma, no modelo de "concorrência perfeita, o longo prazo é determinado pelo período de tempo que se leva para variar todos os inputs" (CORCORAN, 1984, p. 93). 
A equação (5) revela as relações de $n$ e $r$ que promoveriam a completa dissipação das rendas. CORCORAN (1984) substitui a equação (5) na equação (3) e obtém uma nova equação:

$$
\mathrm{T}=\mathrm{P} \quad \text { Equação (6) }
$$

Com base na equação (6), o autor conclui que "no equilíbrio de longo prazo o total das despesas de todos os competidores será igual ao payoff" (CORCORAN, 1984, p. 92). Ademais, esta igualdade ocorrerá independente do custo marginal uma vez que T será invariante em relação a r. Diante desta constatação, Corcoran (1984) considera incorreta a proposição - presente em Tullock (1980) - de que 0 incremento dos custos marginais contribuiria para reduzir o total das despesas em rent seeking. Segundo o primeiro autor, é possível observar através da equação (2) que quando r decresce, ou seja, quando os custos marginais se ampliam, as despesas individuais decaem. No entanto, também é possível constatar através da equação (4) que com o decréscimo de r, os lucros crescerão o que tende a estimular novas entradas. 0 "acréscimo resultante no número de competidores compensará exatamente o declínio das despesas individuais e, por consequiência, a despesa total [em rent seeking] permanece constante" (CORCORAN, 1984, p. 92). Não obstante esta crítica, o autor estudado considera válida a proposição (defendida inicialmente por Tullock [1980]) que o rent seeking poderia ser minimizado mediante a restrição do número de jogadores.

Higgins, Shughart II, Tollison (1985) e Tullock (1984) realizam algumas críticas às proposições de Corcoran (1984). Um primeiro aspecto criticado diz respeito à equação (5). 0 número de competidores necessário para que as rendas sejam completamente dissipadas é independente em relação ao valor do prêmio P. "Isso sugere que para um dado valor de r, o mesmo número de pessoas ingressará no jogo independentemente se o prêmio for igual a $\$ 1$ ou se o prêmio for de $\$ 100.000 "$ (HIGGINS; SHUGHART II; TOLLINSON, 1985, p. 250). Esse resultado claramente contrariaria o senso comum.

Os autores estudados apontam um segundo problema na análise de Corcoran (1984): "[...] o que Corcoran falha em perceber... é que para o resultado de lucro-zero fazer sentido, $\mathrm{r}$ deve estar restrito ao intervalo $(1,2)$ " (HIGGINS; SHUGHART II; TOLLINSON, 1985, p. 256). A análise do gráfico abaixo, obtido a partir da equação (5) ajuda a esclarecer esta última colocação. 
Gráfico 3 - Combinações de n e r para que o valor do prêmio seja dissipado através do rent seeking

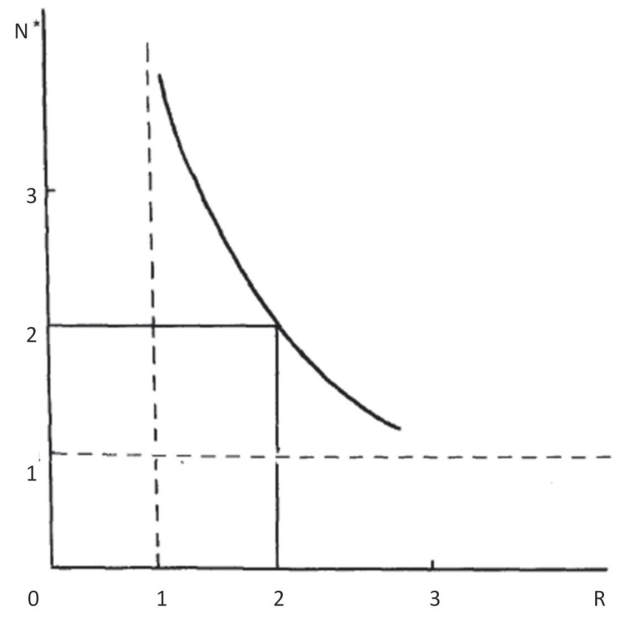

Fonte: Higgins, Shughart II e Tollinson (1985, p. 250)

Conforme ressalta Tullock (1984), nos pontos onde $\mathrm{r}<1$, o valor das despesas de todos os participantes é menor do que opayoffe, desta forma, as rendas não serão completamente dissipadas no longo prazo (situação denominada de underbidding). Higgins, Shughart II e Tollinson (1985) analisam as demais combinações de n e r presentes no gráfico acima:

Quando $\mathrm{r}=1$, underbidding é obtido para qualquer valor finito de $\mathrm{n}$; necessitase de um número infinito de jogadores para ocorrer a dissipação total das rendas. Conforme $\mathrm{r}$ assume valores superiores a $1, \mathrm{n}$ decresce assintoticamente para a unidade. Desta forma, $r$ deve se situar no intervalo $(1,2)$ para que 0 resultado lucro-zero faça sentido. Apenas se estivermos dispostos a assumir 1 $<\mathrm{r}<2$ haverá um valor ótimo de n que dissipará todas as rendas (HIGGINS; SHUGHART II; TOLLINSON, 1985, p. 250).

Desta forma, estes autores concluem que a expansão do "modelo de Tullock para permitir (novas) entradas, promoverá a dissipação de todas as rendas apenas sob algumas condições bem restritas" (HIGGINS; SHUGHART II; TOLLINSON, 1985 p. 250, grifo nosso).

Tullock (1984) ressalta a existência de problemas mesmo no intervalo $1<\mathrm{r}<2$. 0 economista citado utiliza a equação (5) para calcular diferentes combinações de $n$ e $r$ neste intervalo. Se $r=1,5$ n será igual a 3. Neste caso, não ocorre nenhum problema e o valor do prêmio será completamente dissipado 
conforme Corcoran (1984) havia suposto. No entanto, se $\mathrm{r}=1,6$, n será igual a 2,67, o que não constitui um número inteiro. Neste segundo caso, se apenas dois competidores participarem, o valor do payoff não será completamente dissipado e os competidores obterão lucros; já se três participantes ingressarem no jogo, todos eles sofrerão perdas líquidas. Ocorre um sério "problema de descontinuidade nesse modelo, de tal forma que mesmo se $1<r<2$ não se pode afirmar que 0 valor do (prêmio) será necessariamente dissipado" (FIANI, 2003, p. 10).

\section{ANÁLISES EMPÍRICAS SOBRE OS GASTOS DE RENT SEEKING NO SETOR DE PETRÓLEO BRUTO}

Dougan e Snyder (1992) consideram que a regulação do setor de petróleo bruto representa uma das poucas políticas regulatórias que possuem estimativas confiáveis, tanto para os gastos em lobbies quanto para a magnitude das transferências de rendas propiciadas pela regulação. Ademais, este setor atenderia uma importante prerrogativa dos modelos padrões de rent seeking - a existência de distintos grupos de interesses que investem largas quantias tanto a favor como também no sentido contrário às propostas de regulação. Desta forma, "se a proporção dos custos de rent seeking em relação às rendas geradas não for próxima da unidade neste caso, é improvável que esta razão apresente este comportamento nas demais políticas existentes" (DOUGAN; SNYDER, 1992, p. 201).

Chubb (1983) identifica quatro grupos afetados pela regulação do petróleo. Para estimar os gastos em rent seeking, o autor contabilizou o orçamento total (período 1977 - 1978) dos escritórios em Washington pertencentes aos quatro grupos de interesses identificados. Chubb (1983) demonstra que os grandes produtores (grupo 1) e os usuários comerciais (grupo 2) representam os principais competidores por influência no processo de elaboração da legislação federal. Os escritórios em Washington do primeiro grupo gastaram anualmente 75 milhões de dólares, enquanto o segundo grupo gastou 43 milhões. Por sua vez, o lobby das pequenas refinarias, comerciantes independentes e revendedores (grupo 3) foi de 1,62 milhões de dólares. Por último, o lobby dos consumidores (grupo 4) foi de apenas 486 mil dólares. "Arredondando para cima propositalmente para compensar a omissão dos orçamentos de pequenos escritórios, podemos estimar um total de despesas anuais de aproximadamente 125 milhões de dólares ${ }^{10}$ ",

${ }^{10}$ Dougan e Snyder (1992) emitem uma importante ressalva a respeito da dificuldade de
mensuração dos custos de lobbying. Constitui-se praticamente impossível estimar o tempo
gasto pelas empresas não situadas em Washington nas questões políticas, e/ou separar o tempo
gasto pelos legisladores e burocratas nas questões relacionadas ao rent seeking do tempo 
(DOUGAN; SNYDER, 1992, p. 201). De que forma este valor estimado se compara com o total das rendas anualmente transferidas pelo programa de regulação dos direitos sobre o petróleo que vigorou no mesmo período?. Dougan e Snyder (1992) fornecem a resposta:

De acordo com Kalt (1981, p. 216), em 1978 [...] o efeito dos controles e direitos (sobre o petróleo bruto) impôs perdas de $\$ 14,3$ bilhões aos produtores, 0 que correspondeu a ganhos para as refinarias de $\$ 8,5$ bilhões e $\$ 4,7$ bilhões para os consumidores dos produtos de petróleo. Se nós assumimos que todas as refinarias também produzem o petróleo bruto que elas utilizam, então elas não foram nem beneficiadas nem prejudicadas pelo programa, a renda transferida será aquela recebida pelos consumidores. Nota-se que isso implicara um custo em termos de perda de eficiência de 1,1 bilhões, 0 que representa a diferença entre os 4,7 bilhões ganhos pelos consumidores e a perda líquida $(14,3-8,5)$ dos produtores. Assim, o caso avaliado indica que não apenas os custos com lobby foram pequenos em comparação com a renda redistribuída pelo programa de direitos $(2,7 \%)$, mas que [...] os custos de lobbyng representaram apenas $11 \%$ dos custos sociais do programa (DOUGAN; SNYDER, 1992, p. 202).

Desta forma, os autores citados anteriormente concluem que as estimativas disponíveis a "respeito das despesas com lobby e das rendas transferidas sob a regulação federal do petróleo bruto contradizem a hipótese que as rendas serão completamente dissipadas através da competição política" (DOUGAN; SNYDER, 1992, p. 202).

\section{Conclusão}

É possível observar a existência de uma vasta literatura econômica e política sobre o crescimento da desigualdade e da pobreza nos países que se submeteram ao receituário liberal. Embora o estudo destas mazelas se situe fora do escopo traçado para este artigo, convém ressaltar que as constatações presentes no terceiro tópico tendem a reforçar o impacto destas denúncias críticas. As relações de complementaridade podem ser comprovadas através do arrolamento das principais políticas públicas associadas ao neoliberalismo: a desregulamentação

gasto nas demais atividades rotineiras destes profissionais. Obviamente, a estimativa de Chubb (1983) não incorpora estes custos. No entanto, "todos estes custos teriam que ser um múltiplo enorme das estimativas de Chubb (1983) para causar alguma alteração nas conclusões" (DOUGAN; SNYDER, 1992, p. 203) apresentadas nos próximos parágrafos. 
econômica, a abolição das políticas industriais setoriais e das demais intervenções estatais na concessão de direitos de propriedade, liberalização comercial, políticas de privatização, etc. Por trás de todas estas prescrições, parece residir o pressuposto da total dissipação das rendas através das atividades de rent seeking. Desta forma, a contestação deste pressuposto tende a minar, ainda mais, a legitimidade das políticas liberais já seriamente abalada pelas denúncias a respeito dos efeitos socioeconômicos perversos do Consenso de Washington.

À luz dos estudos apresentados no terceiro tópico, é possível concluir que a hipótese da total dissipação das transferências econômicas, oriundas da intervenção estatal na economia através das atividades de rent seeking, não possui sustentação teórico-empírica consistente. Do ponto de vista teórico, não existe um consenso dentre os proponentes da teoria do rent seeking a respeito da ocorrência deste resultado extremo. Tanto o modelo de Tullock (1980), quanto as considerações de Higgins, Shughart II e Tollinson (1985) e de Tullock (1984) sobre o comportamento das rendas no longo prazo demonstraram a possibilidade de existência de jogos nos quais algum lucro permanecerá para os jogadores. No tocante à constatação empírica, Dougan e Snyder (1992) e Chubb (1983) demonstram que as despesas com lobby foram pequenas (somente 2,7\%), em comparação com a renda transferida pelo programa de direitos sobre o petróleo bruto nos EUA durante os anos 1977 e 1978. Desta forma, a total dissipação das rendas parece representar um caso particular e não uma propriedade geral imanente à ação estatal, conforme propunham os primeiros trabalhos sobre o rent seeking.

Dado este caráter particular, a determinação dos efeitos da ação estatal na economia será muito mais complexa do que suponham os primeiros estudos sobre o rent seeking: de fato, ocorrerá a dissipação de uma parcela da renda gerada pela intervenção estatal, mas também poderá ocorrer algum acréscimo de riqueza. 0 montante deste acréscimo e os potenciais beneficiários dependerão, por sua vez, da configuração institucional vinculada à atribuição/distribuição dos direitos sobre as transferências geradas. Desta forma, seria muito mais proveitoso para sociedade submeter as políticas públicas a um exame caso a caso, ao invés de assumir a total dissipação das rendas como uma propriedade de validade geral inibidora da ação estatal. Por último, avaliamos que a defesa de políticas públicas liberais, baseada na teoria de rent seeking, possui reduzida legitimidade. A justificação de políticas públicas não pode se basear em uma teoria cuja insistência nos efeitos negativos da intervenção estatal na economia obedece muito mais a crenças anti-estatais, do que a resultados analíticos gerais e bem evidenciados. 


\section{REFERÊNCIA}

BUCHANAN, James M. Rent seeking and profit seeking. In: BUCHANAN, James M.; TOLLISON, Robert D.; TULLOCK, Gordon (Ed.). Toward a theory of the rentseeking society. College Station: Texas A \& M University Press, 1980. p. 3-15.

CHUBB, John E. Interest groups and the bureaucracy. Stanford: Stanford University Press, 1983.

CORCORAN, William J. Long-run equilibrium and total expenditures in rentseeking. Public choice, Dordrecht, v. 43, p. 89-94, 1984.

DOUGAN, William R.; SNYDER, James M. Are rents fully dissipated. Public choice, Dordrecht, v. 77, n. 4, p. 793-813, 1992.

FIANI, Ronaldo. Uma avaliação crítica da teoria de rent seeking. Rio de Janeiro: Instituo de Economia da Universidade Federal do Rio de Janeiro, 2003. (Série Seminário de Pesquisa).

HIGGINS, Richard S.; SHUGHART II, William F; TOLLISON, Robert D. Free entry and efficient rent-seeking. Public choice, Dordrecht, v. 46, p. 247-258, 1985.

KRUEGER, Anne 0. The political economy of the rent-seeking society, American Economic Review, Princeton, v. 64, p. 291-303, 1974.

POSNER, Richard A. The social costs of monopoly and regulation. Journal of Political Economy, Chicago, v. 83, p. 807-827, Aug. 1975.

PINDYCK, Robert S.; RUBINFELD, Daniel L. Microeconomia. São Paulo: Makron Books, 1994.

TOLLISON, Robert D. Rent-Seeking: a survey. Kyklos, Basel, v. 35, p. 575-601, 1982.

TULLOCK, Gordon. Long-run equilibrium and total expenditures in rent-seeking: a comment. Public choice, Dordrecht, v. 43, p. 95-97, 1984.

The welfare costs of tariffs, monopolies, and theft. Western Economic Journal, Oxford, v. 5, p. 224-232, 1967.

Efficient rent seeking. In: BUCHANAN, James M.; TOLLISON, Robert D.; TULLOCK, Gordon (Ed.). Toward a theory of the rent-seeking society. College Station: A \& M University Press, p. 97-112, 1980.

. The origin of Rent-Seeking concept. International Journal of Business and Economics, Arlington, v. 2, n. 1, p. 1-8. 2003. 